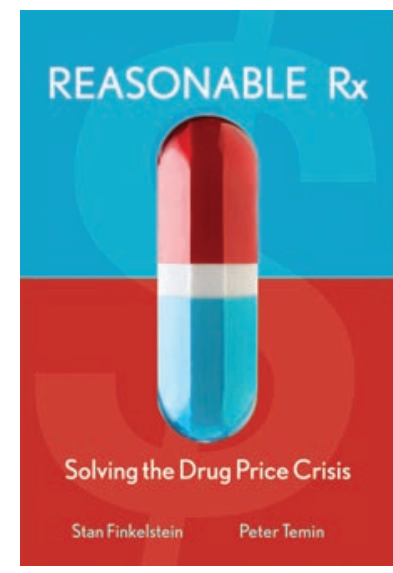

\title{
Reasonable Rx
}

\author{
Solving the drug price crisis
}

Stan Finkelstein and Peter Temin

FT Press. Upper Saddle River, New Jersey, USA. 2008.

208 pp. \$27.99. ISBN: 978-0-132344494 (hardcover).

\section{Reviewed by Jack Hoadley}

Health Policy Institute, Georgetown University, Washington, DC, USA.

E-mail: jh7@@georgetown.edu

easonable Rx: solving the drug price crisis examines how prescription drugs are discovered, marketed, and priced in the United States. Stan Finkelstein, a physician, and Peter Temin, an economist - both based at the Massachusetts Institute of Technology - bring highly distinguished backgrounds to this critique of the prescription drug business. What makes the book significant is that the authors go beyond just taking shots at how the pharmaceutical industry works today and propose a potential solution that deserves to be read and given serious attention by the policy community.

Prescription drugs are big business in the United States. Collectively, we spent over $\$ 200$ billion for prescription drugs in 2006, which according to the federal government's estimates represented 10\% of overall public and private health expenditures. Although drug prices rose a little less rapidly in the last five years compared to the previous decade, largely because some best-selling drugs lost patent protection and became available in generic form, Americans continue to use more drugs, and many struggle to pay for prescriptions.

In the book's first four chapters, the authors discuss how the drug industry operates and how the industry evolved from the mid-twentieth century to the present. These chapters are filled with interesting details on such issues as how risk operates in this market, how manufacturers seek to create markets for their products, and the role of advertising. The examples will probably be familiar to some readers and not to others, but the point is to illustrate the ways in which the market is failing to meet society's needs. In one telling example, the authors note that the blockbuster drug Singulair, a top-selling oral treatment for asthma, might be better targeted if a genet- ic test could be developed to identify who is most likely to respond favorably to it. But the manufacturer would see sales volume drop if only those passing the test bought the drug, leading to either lower revenues or higher prices. No such biomarker for Singulair exists today.

The authors use the Medicare Part D drug benefit (a federal program to subsidize the cost of prescription drugs for Medicare beneficiaries) as a case study for a chapter titled "How not to lower drug prices." They call it "fatally flawed" for trying to expand access to drugs while preserving the way the pharmaceutical industry works. Although the authors get a few details wrong about Part D, they make the valid point that the program's reliance on essentially the same market mechanisms already used by employer-based health plans to control spending is unlikely to change the underlying factors that make drugs expensive.

On drug development, the authors ask why the industry's resources for research and development have been squandered (to use their term). They assert that three components - money, science, and incentives - are essential to develop new medicines. For the most part, the money is there. The science, however, is increasingly taking a back seat to business considerations, and incentives are misaligned.

The book concludes with a prescription for getting the system back on track. The primary argument in the final chapter, titled "How to lower drug prices," is to separate the business of developing new drugs from the business of marketing and distributing drugs to patients and doctors. Finkelstein and Temin believe that splitting these functions, which would be akin to the break up of AT\&T in the early 1980s, will allow drug companies to concentrate on developing new products without concern for whether the market for a drug is large enough to allow substantial profits. Thus, in the Singulair example, there would be no disincentive to identify an effective biomarker. The result should be the development of more effectively targeted treatments and lower prices and spending.

The link between the newly separated industries would be an "independent, public, nonprofit Drug Development Corporation (DDC)." The DDC would pay the development company for the license after a drug is approved for market by the FDA. In turn, it would auction the rights to sell the drug to a distribution company. The payment to the development company would not necessarily reflect solely the auction price received from the distribution company, since the DDC would be able to prioritize and pay differentially, based on its assessments of medical and societal needs. For example, the developer of a new malaria drug, which would not demand a high sales price, might receive a higher payment, whereas the developer of the latest "me-too" drug in a crowded drug class might receive a payment lower than the auction price. For the most part, the authors propose a market-based approach but with a revised market structure and set of players. But as in these latter examples, pure market forces would be modified to serve other societal goals.

This easily readable book challenges its readers to think hard about two fundamental questions: why has drug innovation dropped off in recent years, and why are drugs still so expensive? Not all readers will find this policy proposal to their liking, and those that do may want to modify the approach in various ways. But the book provides a thought-provoking set of ideas to which readers should give some serious thought. 